\title{
DEVELOPMENTS IN MUSIC TECHNOLOGY: Hybrid Activity in Popular Music
}

By Jeremy Wade Morris

\section{Track 1: Music technology and hybridity}

he most critical [issues] to which we should turn our attention
are those that have consequences for the movement of music within and through different (and sometimes altogether new) spaces, such as changes in sales mechanisms, Internet broadcasting, the use of computers for producing, consuming and distributing music, and the personalisation of musical tastes and behaviours. (Jones, "Music and the Internet" 225)

Since the invention of recorded sound, music and the technology with which it is recorded have been entwined. From the phonograph to the mp3, the history of popular music production, distribution and consumption in the twentieth century is one marked by various technological innovations (see for example Coleman, 2003; Garofalo, 1999). Currently, new digital recording technologies are facilitating changes to the music making process (Théberge, 1997). Sophisticated software programs such as ProTools and Nuendo offer near-professional song recording, mixing and mastering abilities while Reason, Acid, plus a host of other programs encourage the manipulation of original or sample-based sounds. Innovations in the technologies of consumption are causing similar impacts to the listening process (Bull, 2000). Digital jukeboxes, mp3 players and new business models from the likes of iTunes and Napster 2.0 are affecting the way we receive and use music. In many ways, the processes associated with production and consumption are currently converging into one machine: the computer.

If we take hybridity as a heterogeneous composition, a coming together of disparate or separate elements, then the field of 
popular music is ripe with examples. As the computer assumes a central role in the music process and an ever-increasing amount of music is created and consumed by such familiar activities as dragging, dropping or clicking a mouse, hybrid compositions - combinations or re-appropriations of different musical sources- are easier to create than ever. From mash-ups to sound libraries, there is a nearly endless stream of hybrid activity to research in popular music.

To that end, this conference paper provides a broad overview of some of the hybrid practices that emerge as both artists and listeners make use of new digital music technologies. Drawing broadly on Jones' "Music and the Internet" (2000) and PaulThéberge's Any Sound You can Imagine (1997), I consider the issues that arise as an ever-increasing amount of music production and consumption becomes mediated by digital and computer-based technologies. While glancing over the issues of copyright and authenticity that arise, I focus primarily on Jones' call for increased research on the impact of digital technologies on the production, consumption and distribution of music (Jones 2000). Presented in eight interrelated sections (Tracks 1-8), the paper weaves together examples of hybridity with mediations on the potential effects of technological changes in the music process. Throughout, I assert that new digital music technologies facilitate (perhaps even encourage) the hybridization of sounds, songs and practices.

\section{Track 2: The case of Grey Tuesday}

February 24, 2004 will hopefully go down in history as "Grey Tuesday." On this day, more than 300 websites and blogs across North America staged an on-line music protest in support of some "illegal" music files created by underground hip-hop artist Brian Burton, a.k.a. DJ Danger Mouse (Werde, 2004). The songs, known collectively as The Grey Album, were a compilation of innovative hip hop remixes featuring the lyrics of rapper Jay-Z's Black Album set to the music and sounds of the Beatles' White Album. Hence the resulting hybrid: The Grey Album (2003). 
The novelty and creativity of Danger Mouse's production helped the tracks spread quickly through the underground and eventually on to the internet. But the hybrid remix violated copyright law, so EMI promptly sent "cease and desist" letters to Danger Mouse and anyone offering the songs on their site(s) (Werde, 2004). Grey Tuesday was organized as a form of protest against these letters; it was a "day of coordinated civil disobedience," an act of defiance against overbearing industry control (DownhillBattle.org, 2004). Whether or not Grey Tuesday made enough noise to gain a permanent place in history books remains to be seen. On the one hand, the event is but one example of the rampant music piracy that is now possible thanks to digital production software such as Acid (discussed below), and distribution technologies such as mp3 files and peer to peer networks. On the other, the album and the ensuing protest underscores an issue beyond the music. At its roots, Grey Tuesday shows that traditional legal aspects of the music product (e.g. copyright, authenticity and intellectual property) are antiquated in light of new technologies.

Skeptics might not see the creativity or innovation involved with The Grey Album. On the surface, Danger Mouse's idea to put rap lyrics over The Beatle's music seems more of a novelty act than an artistic endeavour. This line of reasoning, however, ignores the complexities involved in producing an album of this nature. Danger Mouse plucked every drum sound, hi hat, bass line and sound sample from its original context and then he meticulously edited and digitally manipulated them to fit the beat, tempo and feel of the lyrics. Without wanting to sound technologically deterministic, the extent of the hybridity on this album simply would not have been possible without the help of new digital recording software; in this case, a program called Acid Pro (Moss, 2004). The software gives users the ability to alter and re-format song characteristics such as tempo and pitch, allowing for the seamless integration of multiple sources. In short, users have a level of control over other people's material that was previously not possible with other recording devices. Along with 
Acid Pro, the Grey Album is also undoubtedly a product of Danger Mouse's creativity and talent with sound in general, but the case firmly shows the growing importance and impact of computers on the music process. From the software used to create the hybrid songs to the websites created in defence of the "illegal" files, the digital nature of Grey Tuesday is undeniable.

\section{Track 3: The home studio IS the computer}

For musicians, accessing or building a recording studio used to be one of the most expensive parts of the recording process (Théberge 231). Thanks to advances in micro-processor power, recording software, and instrument-computer interfacing, a computer loaded with the proper software can provide high quality recording options for professional and amateur musicians alike (Middleton 66). Integrated software packages combine numerous recording and production tasks. Once reserved solely for "electronic" music, computers are now employed by all kinds of studios and musicians. As such, musicians must become increasingly proficient at computer use while computers must become increasingly adept at being instruments (a point I will return to later in the paper).

The computer is now, in many cases, a central device for the consumption of music. Hard drives can now store massive amounts of music which users can obtain from both authorized and unauthorized on-line music libraries (e.g. Bearshare, iTunes, Kazaa, LimeWire or Napster). Just as recording tape and the compact disc changed our listening behaviours, so too have digital files. Virtual players (e.g. MusicMatch Jukebox, Real Player or Windows Media Player) and portable mp3 (e.g. iPod) devices give consumers novel ways to play music. Playlists can be created for different events and moods or song selection can be left to the whim of the random shuffle function. While random shuffle exists on compact disc players, the size of mp3 digital music libraries creates unique possibilities for the use of random mode. As music critic Alex Ross enthusiastically notes: "I have seen the future, and it is called Shuffle - the setting on the 
iPod that skips randomly from one track to another" (Ross 154). While there is a certain amount of randomness to the selections, Ross argues that the sequence of the random songs serves to make connections between the disparate sources in his music collection. Rappers and minimalist classical composers fuse and intertwine to create a hybrid playlist. Music, he says, is "freed from its fatuous self-definitions... music is music" (Ross 154).

Ross' infatuation with the shuffle function comes in part from the fact that playlists offer listeners the ultimate in customization while at the same time offering them enough flexibility and randomness to keep boredom minimal. Users have increasing amounts of control over the music they are consuming, though they can choose to relinquish it to the artists or to the device at will. Computer-based music players are not simply devices of reproduction; they allow users to be part of the production process. That being said, there is a useful reminder on the back of Canadian musician Danny Michel's 1999 album Fibsville: "Just say no to random shuffle mode" (Fibsville, 1999). For Ross, random shuffle lets music roam free; for artists like Michel, music deserves a sense of order and structure.

\section{Track 4: Seeing sound}

As the computer gains a more prominent role in audio production and consumption, visual aspects of music are affected. On the production side, software interfaces display a standard visual representation of sound (see Figure 1).

Arguably sound has been visual since musical notation, but visual representations of digital audio differ in their malleability. Acid, Cubase and other software programs all feature visual representations of sound waves which become, like much other digitized data, a string of zeroes and ones that can be manipulated endlessly through algorithms. Verses, choruses, melodies and harmonies can all be drawn and sequenced based on sight, just like paragraphs or sentences that are cut and pasted in a word processor. Through visual 


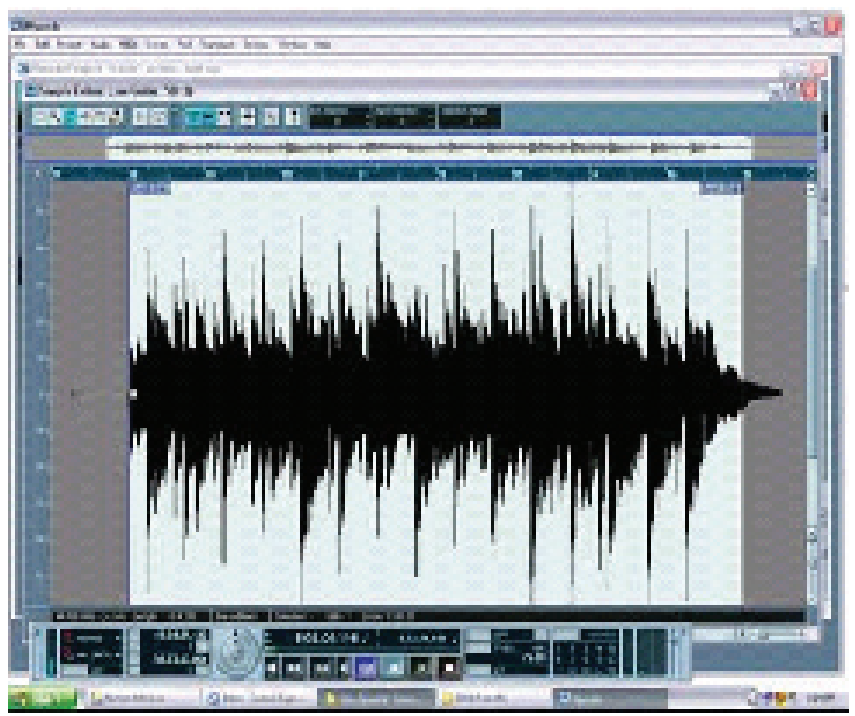

Fig. 1 - Visual representation of a sound wave taken from Nuendo 2.0

means, sounds can be sonically altered. Whereas audio engineers of the past relied on their ears to create, newer musicians and producers are increasingly relying on their eyes. They must not only hear music, they must see it as well.

Consumers, on the other hand, are in a sense being presented with less visual data. As an increasing amount of music is available in digital format, traditional imagery associated with the music product is affected. I believe that the images associated with the music product are an important part of the music consumption experience, affecting the way we make meaning out of the music and the artist. With mp3 and wav files, album packaging is reduced, at best, to a thumbnail image. As more and more digital music gets transferred to iPod's and other portable players, artists and the imagery that typically accompanies them is reduced to text. 


\section{Track 5: Loops, samples and the search for sounds}

While the visual aspect of music is interesting, sounds are still a necessity for making music. Computers may have become increasingly adept at reproducing real instrument sounds, but a key component of new recording programs like Acid or Reason is their sampling and looping functions. In the case of the Grey Album, Danger Mouse used the technology to sample and re-arrange well-known recordings. However, these programs also offer users banks of usable sounds that are not from recognizable (or copyrighted) sources. These sound libraries give users access to instruments and sounds they may not be able to create themselves. If a user cannot play violin or cello, they can simply purchase a CD with samples of renowned string players and begin creating. Rather than relying on instruments to create the sounds they need, musicians search for pre-recorded sounds from which to create music.

This represents, as Théberge argues, a new form of practice where "the process of selecting the 'right' pre-fabricated sounds and effects for a given musical context has become as important as 'making' music in the first place" (Théberge 200). The line blurs between reproduction and production as the search for sounds becomes as important as playing an instrument. Popular music producer Brian Eno notes that "what has become interesting is the idea that artists are people who specialize in judgment rather than skill” (qtd. in Théberge, 242). Eno's quote underscores the realization that when musicians increasingly rely on a shared bank of sounds; the true task becomes one of differentiation. If these programs offer standard banks of pre-recorded loops, audio software users need to find unique ways to present similar sounds. Musicians are encouraged to produce through reproduction; to produce new sounds through the use of sounds they themselves have not created.

\section{Track 6: The case of GarageBand}

The proliferation of user-friendly music production software like GarageBand offers more and more consumers the chance to produce 
through the use of loops and samples. GarageBand is a very basic recording program that comes bundled with new iMacs. We need only look at the manner in which Apple introduced the application in 2004 to realize the importance loops and samples have assumed in the computer music making process:

You don't have to play the piano. You don't have to read music. You don't even have to have rhythm. If you know what you like when you hear it, you can make your own kind of music.... The easiest way for anyone - pro or novice alike — to perform, record and create music, GarageBand turns your Mac into an anytime anywhere digital recording studio — complete with instruments, pre-recorded loops, amps, effects and editing tools.... You'll be spinning the music of the spheres in no time.... If you know how to click, drag and drop, you're well on your way to becoming a GarageBand wiz. (Apple.com, 2004)

While the case of GarageBand speaks to the diffusion of sampling and looping to a larger audience, of course, loops and samples are not exclusive to computer music production and consumption. The practice has been around since hip-hop and DJs. Depending on how broadly one defines sampling and looping, the process can be traced all the way back to musique concrète. GarageBand, then, is interesting not because it is a new technology that has spawned a revolutionary practice, but rather because it is indicative of how new recording software has incorporated practices like looping and sampling as basic features, and users have begun to rely on them as an integral part of the production process.

\section{Track 7: Music without instruments}

The increasing reliance on loops, samples and other pre-recorded material means focus is shifting away from requiring traditional musical instruments in the home studio. In addition to the significant amount of music made from loops, samples and otherwise available material, new digital software programs provide patches 
and algorithms that imitate instruments. In many cases, traditional guitars, pianos or drums are not needed to make guitar, piano or drum sounds. While this shift arguably began occurring with the birth of synthesizers, users were still required to learn how to play the instrument (e.g. the keyboard). Computer users, on the other hand, are already familiar with their instrument; they only need to learn to play it differently. Although this subsection's title was exaggerated for emphasis, it was intended to highlight the increasing amount of non-instrument based music that can now be created. ${ }^{8}$ There's no need to play an instrument when GarageBand and its sound library, for example, claim to be able to turn anyone who can work a computer mouse into a musician. Does the concept of musical skill need to be re-assessed based on how good a user is with a particular piece software?

\section{Track 8: Music about music}

The cases of hybrid activity examined in this paper are quite recent and may leave some with the false impression that hybridity in the music industry is a new phenomenon. Many of the practices and behaviours in question have historical antecedents that could not be discussed within the scope of this paper. I do not wish to claim that hybridity in music is solely the result of developments in computer technology. Instead, I believe the technologies and software discussed in this paper facilitate and perhaps encourage hybrid activity on the part of producers and consumers. Combined with peer-to-peer and other means of distribution, they foster an environment where hybrid entities like the Grey Album can have an instant audience beyond underground clubs. Reproductions of drum loops or horn melodies become legitimate parts of the production process.

Traditionally, studies of the popular music industry dissect

8 "Non-instrument based" refers here to the fact that direct interaction with an instrument on the part of the creator is not needed; instruments may still be involved in the process (i.e. through loops and samples) but their use is indirect. 
objects in categories: production, consumption, distribution or production and reproduction. To some extent I have tried to maintain these classifications but, as scholars like Théberge and Jones point out, the exercise is becoming increasingly futile: "Indeed, it could be argued that with the introduction of digital technologies and their attendant uses, the distinction between production and consumption has become increasingly blurred and, to a certain degree, meaningless" (Théberge 242). The hybrid activities discussed here speak to this blurring of boundaries. Rather than simply cases of production and reproduction, musicians and consumers are engaging in the practice of production through reproduction.

In discussing the impact of the turntable, Charles Mudede proposes the concept of meta-music. Meta-music, he argues, is "less 'music', per se, and more 'about music' ... music made out of and about other music" (Mudede, 2003). Applying Mudede's concept to the hybrid practices examined here is instructive as these practices are as much comments on music as they are music. As new digital technologies enable an increasing amount of music made from other music, and as our practices of music seeking and listening force collisions between disparate elements, a kind of meta-music is created. The Grey Album works, at some level, because of the comment it makes by associating two albums so stylistically and indeed, historically (20 years) far apart. The same can be said about the hybrids created using the random shuffle mode. Some listeners will hear the comments that occur between the songs; others will simply hear music.

\section{Works Cited}

Apple.com. "GarageBand Homepage." 2004. 2 June 2004 <http://www.apple. com/ilife/garageband/>.

Bull, Michael. Sounding out the City: Personal Stereos and the Management of Everyday Life. Oxford: Berg, 2000. 
Coleman, Mark. Playback: From the Victrola to Mp3, 100 Years of Music, Machines, and Money. New York: De Capo P, 2003.

DownhillBattle.org. "Grey Tuesday.” 2004. 25 Feb. 2004 <http://www. downhillbattle.org>.

Danny Michel. Fibsville. Sound Recording, 1999.

Garofalo, Reebee. "From Music Publishing to Mp3: Music and Industry in the Twentieth Century." American Music 17.3 (1999): 318-53.

DJ Danger Mouse. The Grey Album. Sound Recording, 2003.

Jones, Steve. "Music and the Internet." Popular Music 19.2 (2000): 217-30.

Middleton, Chris. The Complete Guide to Digital Audio. Boston: Muska and Lipman Publishing, 2003.

Moss, Corey. "Grey Album Producer Danger Mouse Explains How He Did It.” 2004. 22 June 2004 <http://www.mtv.com/news/articles/1485693/ 20040311/jay_z.jhtml?headlines=true>.

Mudede, Charles. "The Turntable.” CTHEORY A126 (2003).

Ross, Alex. "Listen to This." The New Yorker. Feb. 16 \& 23 2004: 146-55.

Théberge, Paul. Any Sound You Can Imagine: Making Music/Consuming Technology. Hanover, NH: Wesleyan UP, 1997.

Werde, Bill. "Defiant Downloads Rise from Underground." New York Times Feb. 25 2004, sec. E: 3. 